\title{
A formação das religiões afro-brasileiras: A interferência do sincretismo religioso.
}

\author{
The development of the Afro-Brazilian religions: The interference of \\ religious syncretism
}

Rita Suriani Lamas ${ }^{1}$

Resumo: Este artigo discorre sobre o processo de sincretismo religioso que culminou na formação das religiões afro-brasileiras. Apresentando a definição de sincretismo adotada no trabalho, o texto aborda a influência do catolicismo ibérico, na condição de religião oficial do Brasil colônia, na cosmovisão dos negros escravizados trazidos ao país. A partir de autores como Roger Bastide e Volney Berkenbrock o presente trabalho se mostra como uma pesquisa introdutória ao modo como se deu a adaptação dos praticantes das religiões africanas em terras brasileiras.

Palavras-Chave: Religiões afro-brasileiras, candomblé, umbanda, sincretismo.

Abstract: This paper discusses the process of religious syncretism that culminated on the development of the Afro-Brazilian religions. Presenting the definition of syncretism of this paper, the text addresses the influence of the Iberian Catholicism in the form of the official religion of Colonial Brazil, as viewed by enslaved negroes brought to the country. From the viewpoint of authors like Roger Bastide and Volney Berkenbrock, the present paper presents an introductory research to the adaptation of those who practiced African-based religions in Brazilian territory.

Keywords: Afro-Brazilian religions, Candomblé, Umbanda, syncretism.

\section{Introdução}

O campo religioso brasileiro é um espaço caracterizado por uma forte presença do sincretismo religioso, apesar do destaque cristão/católico (SANCHIS, 1997, P.105). Ter em mente a palavra "sincretismo" se torna um imperativo quando estudamos temáticas que envolvem as religiões no Brasil. São diversas as análises já realizadas sobre o referido tema, análises que, inclusive, partem de diferentes pontos de vista, como é o caso de estudos realizados por autores como Pierre Sanchis (1997) e José Jorge de Carvalho (1999). A maior parte desses estudos converge em um ponto: A existência marcante do sincretismo religioso.

\footnotetext{
1 Especializanda em Ciência da Religião pela Universidade Federal de Juiz de Fora - UFJF. surianilrita@gmail.com
} 


\section{SACRILEGENS

Pierre Sanchis apresenta o campo religioso brasileiro a partir da hegemonia católica, definindo-a como um "processador de diferenças" (SANCHIS, 1997, p.105). Segundo este autor, desde a invasão portuguesa que transformou o Brasil em colônia lusitana fundou-se em terras latino-americanas um ambiente de intensa vivência entre diversas práticas religiosas, destacando o catolicismo ibérico, as religiões de matriz africanas e as religiões indígenas (SANCHIS, 1997, p.106). Essa abordagem que parte do catolicismo para compreender o campo religioso brasileiro é a mais comum dentre os estudiosos da área (CARVALHO, 1999, p.2). Entretanto, há uma outra perspectiva que também analisa o campo religioso brasileiro e que nos permite compreendê-lo a partir de elementos que são tão presentes na sociedade brasileira quanto o catolicismo: O espiritismo². José Jorge de Carvalho aponta como essa característica espiritual está presente de forma intensa nas mais variadas religiões que compõem o cenário religioso do Brasil, seja nas religiões de matriz africana ou no próprio catolicismo popular, amplamente adotado no país (CARVALHO, 1999, p.5).

Oriundas e inseridas no campo religioso do Brasil temos as religiões afrobrasileiras. Tais tradições religiosas herdaram de seu berço a característica da combinação de elementos, combinação essa fortemente marcada pela presença de traços das religiões africanas e do catolicismo ibérico (BASTIDE, 1971, p.79). É importante destacar que essa junção não aconteceu de forma natural, uma vez que a conversão ao catolicismo foi algo imposto sobre os escravizados (BERKENBROCK, 2019). Entretanto, o menosprezo dos senhores de engenho pelos seus escravos deu margem para que estes conseguissem burlar a suposta conversão -resumida em um batismo, fato que auxiliou no êxito da preservação de parte dos aspectos presentes nas religiões africanas (BERKENBROCK, 2019).

Tendo em vista os temas brevemente pontuados, o presente trabalho busca, portanto, compreender como se deu a formação das religiões afro-brasileiras. Focando na importância do sincretismo entre as religiões africanas e o catolicismo ibérico, este artigo traz pontos considerados importantes sobre a influência da imposição do catolicismo português às cosmovisões dos africanos escravizados. Partindo de contribuições teóricas de autores como Roger Bastide, Volney Berkenbrock e Sérgio Ferreti, o texto analisa como determinados pontos de

\footnotetext{
2 Devo ressaltar que por espiritismo não estamos tratando de alguma vertente religiosa específica, mas de todo um conjunto de atitudes e crenças que incluem algum tipo de relação próxima com seres transcendentes. Para maiores detalhes ler “Um espaço público encantado”, de José Jorge de Carvalho, 1999.
} 


\section{SACRILEGENS

similaridades entre o catolicismo popular e as religiões africanas facilitaram a conservação de aspectos fundamentais a compreensão de vida dos escravizados vindos da África.

\subsection{O Sincretismo Religioso}

Quando se aborda temáticas referentes às religiões no Brasil uma palavra se torna fundamental para desenvolver boa parte dos assuntos: Sincretismo. Trazendo consigo diversas noções e sofrendo consideráveis alterações em seus significados, o termo sincretismo pode ser interpretado como um ponto central para a compreensão do campo religioso brasileiro (SANCHIS, 1997, p.105). Segundo Ferreti, tal palavra carregou em si uma conotação negativa referindo-se a misturas confusas e, até mesmo, sendo interpretada como "heresia contra a verdadeira religião" (FERRRETI, 1998, p.183). O termo sincretismo neste trabalho será abordado como significando uma soma de elementos de diferentes contextos religiosos, abstendo-se de qualquer tipo de juízo de valor sobre os resultados dessas somas (FERRRETI, 1998, p.183).

A fim de elucidar sobre como se deu o surgimento das religiões afro-brasileiras e a importância do sincretismo para tal, devemos contextualizar o ambiente no qual as religiões africanas foram inseridas durante o período de exploração portuguesa em terras brasileiras. A escravização de africanos no Brasil se deu, dentre os diversos motivos, devido ao fracasso da tentativa de escravização dos indígenas que já habitavam o local (MARQUESE, 2006). Entre os séculos XVI e XIX estima-se que chegaram ao Brasil cerca de 3.600.000 africanos para serem escravizados (BASTIDE, 1971, p.52). Poucos são os dados sobre a real origem dos escravizados que chegaram em terras brasileiras, bem como as fontes sobre a cultura e religiosidade dos mesmos, visto que eles compunham uma parcela marginalizada da sociedade (SILVA, 2010, p.1). Além da composição marginalizada, há de se considerar que o mapeamento completo de como se deu a formação da cultura afro-brasileira é um trabalho dificultado devido às características de oralidade que compõem as culturas de origem africanas e, principalmente, ao fato de os documentos oficiais sobre a chegada e permanência dos escravizados no Brasil serem originários de ocorrências policiais ou da Igreja Católica (SILVA, 2010, p.1).

A forma como se concluía a maior parte das negociações dos negros escravizados possibilitava pouca ou nenhuma sobrevivência de seus rituais 


\section{SACRILEGENS

originários, uma vez que a organização dos povos africanos se dava de maneira tribalfamiliar. A escolha dos escravizados que seriam adquiridos pelos compradores brasileiros levava em conta as características físicas do negro ofertado, visando apenas seu bom rendimento para o trabalho que seria exercido. Negros de mesma etnia ou membros de uma mesma tribo/família eram, preferencialmente, separados, a fim de evitar possíveis revoltas e motins contra seus compradores. (BASTIDE, 1971, p.66).

As religiões africanas e as suas formas de compreender as questões que permeiam a vida humana eram essenciais à organização social das tribos da África, sendo a base que sustentava o modo de vida de seus praticantes (BASTIDE, 1971, p.86). Dessa forma, ao serem separados de suas tribos originárias, os escravizados africanos adaptaram a sua religiosidade dentro do que lhes era permitido pelos limites estabelecidos pelo catolicismo popular praticado na colônia portuguesa (BASTIDE, 1971, p.72). Portugal era um reino oficialmente cristão católico e, em decorrência da condenação de qualquer prática religiosa que fugisse a oficial (BERKENBROCK, 2019) os escravizados mascararam suas religiosidades com os panos do catolicismo em busca da preservação de parte de suas crenças. Aos olhos dos senhores de escravos tais práticas eram compreendidas como uma exaltação aos santos católicos que ocupavam um altar nas senzalas (BASTIDE, 1971, p.72).

$\mathrm{O}$ sincretismo entre as religiões africanas pode ser interpretado como sendo o primeiro de muitos outros ocorridos nesse processo que deu origem às religiões afrobrasileira (BASTIDE, 1971, p.87). O culto a diversos orixás em uma mesma casa é uma prática comum entre as religiões afro-brasileiras, entretanto nos países da África cada tribo cultuava apenas um orixá (BASTIDE, 1971, p.90), fato que exemplifica o movimento sincrético ocorrido entre as religiões africanas. Além do sincretismo forçado entre as religiões da África, houve a soma de elementos resultantes desse primeiro movimento e o catolicismo. A junção de aspectos das religiões dos escravizados e do catolicismo português tornou-se um marco importante sobre o que compreendemos atualmente como as religiões afro-brasileiras. A associação entre os orixás e os santos católicos destaca-se como um símbolo fundamental deste movimento sincrético entre as religiões dos brancos e dos negros. Tal associação descoberta pelo pesquisador Nina Rodrigues, como aponta Roger Bastide em seu livro "Religiões Africanas no Brasil”, ganhou força entre os negros escravizados como 


\section{SACRILEGENS

sendo a saída para a conservação das diversas culturas africanas trazidas por eles (BASTIDE, 1971, p.202).

Dentre os diversos fatores que contribuíram para o êxito do sincretismo entre as práticas católicas e as africanas destaca-se a concepção que os portugueses tinham sobre o negro. Bastide aponta que os brancos enxergavam os negros como sendo "um animal sem alma” (BASTIDE, 1971, p.185), portanto, para os colonizadores não importavam a religiosidade de seus escravos, mas apenas o seu corpo. Tal concepção resultou na negligência por parte dos senhores de engenho quanto ao exercício de catequização de seus escravos. $\mathrm{O}$ isolamento social dos negros como pertencendo a uma classe de católicos inferiores também se mostra como um fator importante para o sucesso do sincretismo afro-católico, facilitando a perpetuação de práticas e cultos aos orixás africanos. Os escravizados urbanos contaram com uma relativa ajuda do clero, mesmo que de forma inconsciente, para o desenvolvimento das religiões afrobrasileiras: A criação das confrarias negras. De acordo com os poucos relatos escritos sobre os encontros dos negros, as descrições do que normalmente aconteciam nas confrarias remete a práticas similares às dos cultos de candomblé (BASTIDE, 1971, p.192).

Além da negligência dos senhores de engenho com o que dizia respeito às religiosidades de seus escravizados há o interesse econômico que facilitou a associação entre os santos e os orixás e, consequentemente, o culto a eles. Segundo o que Roger Bastide denomina como "a bíblia dos senhores de engenho", era recomendado que os escravizados possuíssem determinados dias em que pudessem cantar e dançar a fim de evitar a melancolia e aumentar a produção (BASTIDE, 1971, p.72). Essa permissividade, em certa medida, controlada dos senhores de engenho aliada ao que era praticado pelos escravizados nas confrarias culminaram, de certa forma, no sucesso da preservação de parte das religiosidades africanas, como aponta Bastide:

\footnotetext{
“(...)O que sabemos é que em tôda parte onde existiram confrarias de negros, a religião africana subsistiu, no Uruguai, na Argentina, no Peru e na Venezuela, e que essas religiões africanas desapareceram nesses países quando a Igreja proibiu as confrarias de se reunir fora da Igreja depos da missa para dançar” (BASTIDE, 1971, p.79).
}

Outro ponto importante para se destacar sobre fatores que colaboraram com a preservação das práticas religiosas africanas é o fato dos governantes estimularem a preservação de determinados aspectos étnicos de seus escravizados. A justificativa para tal conservação segue a lógica dos conflitos existentes entre as diferentes nações 


\section{SACRILEGENS

que habitavam o continente africano, ou seja, preservando determinadas características que causavam conflitos entre os negros se evitaria o perigo causado pela união e, consequentemente, as revoltas dos mesmos contra os seus senhores (BASTIDE, 1971, p.80).

As características do catolicismo popular português aliadas ao desinteresse dos senhores de engenho no que diz respeito às práticas religiosas de seus escravizados acabaram por contribuir para a conservação de aspectos das religiosidades africanas. Os negros não apresentaram qualquer tipo de resistência a sua catequização, uma vez que essa lhe trazia certo status (BASTIDE, 1971, 181), mas diversos fatores não lhes permitiram o acesso às doutrinas da Igreja Católica, favorecendo o sincretismo e a preservação da cosmovisão africana entre os escravizados. Sobre a forma em que se desenvolveu o sincretismo afro-católico Roger Bastide afirma que:

\footnotetext{
"É compreensível, nessas condições, que o catolicismo negro em geral sobrepõe-se, mais do que a penetrou, à religião africana, e a confraria frequentemente prolongou-se em candomblé. Vilhena reconhece que é impossível arrancar do coração dos africanos os costumes e as cerimônias que 'beberam com o leite de sua mãe' e que seus pais lhes ensinaram; ele afirma que entre mil negros, há talvez um que siga voluntariamente o cristianismo; entre todos os outros, este é imposto de fora, um simples verniz superficial.” (BASTIDE, 1971, p.183).
}

Atualmente o sincretismo entre as religiões afro-brasileiras e o catolicismo é um fato consolidado nos terreiros. A correspondência entre o papel atribuído aos santos católicos pelos habitantes da península ibérica e as funções dos orixás para as sociedades africanas facilitou a consolidação desse sincretismo (BASTIDE, 1971, p.201). Portanto, não se pode pensar em religiões afro-brasileiras ignorando a forte influência que a imposição do catolicismo aos escravizados causou na construção dessas religiões.

\subsection{A Formação Das Principais Religiões Afro-Brasileiras}

Entre as diversas religiões afro-brasileiras a umbanda e o candomblé são expressões de parte da cultura religiosa africana que sobreviveu ao período de escravização. Tendo suas práticas criminalizadas desde a sua chegada ao Brasil, as religiões de matriz africanas, principalmente a umbanda, só conseguiram legitimação frente ao Estado brasileiro a partir da década de 40, durante o governo nacionalista de Getúlio Vargas (TEIXEIRA, 2008). 


\section{SACRILEGENS

A principal narrativa3 sobre o surgimento da umbanda parte da experiência mediúnica de Zélio Fernandino de Moraes, (ISAIA, 2014, p.187). Sendo compreendida como uma religião que valoriza elementos nacionais, como os espíritos indígenas e escravos (PRANDI, 1998, p.156), a umbanda pode ser considerada como o carro chefe que guiou a descriminalização e o reconhecimento das religiões de matrizes africanas no Brasil. Indícios apontam que por uma necessidade de legitimação social parte dos elementos africanizados que compunham a Umbanda, como a tradição oral e o sacrifício de animais, foi deixada de lado. Entretanto, o culto aos orixás e as danças ritualísticas se mantiveram (PRANDI, 1998, p.158).

Durante as primeiras sessões ocorridas em reuniões kardecistas, o espírito indígena do Caboclo Sete Encruzilhadas revelava, através de Zélio Fernandino de Moraes, os preceitos básicos da nova religião (BERKENBROCK, 2019, p.117). Dentre as determinações anunciadas a caridade foi posicionada como sendo o centro do culto umbandista, Jesus como mestre maior, a utilização de roupas brancas durante as experiências mediúnicas e a gratuidade dos atendimentos (BERKENBROCK, 2019, p.119). As primeiras tendas umbandistas foram a Tenda Espírita Nossa Senhora da Piedade, Tenda Espírita São Pedro, Nossa Senhora da Guia, Nossa Senhora da Conceição, São Jerônimo, São Jorge, Santa Bárbara e Oxalá (BERKENBROCK, 2019, p.118). Nota-se pelas denominações das tendas a forte influência de aspectos do catolicismo e do espiritismo kardecista sobre a consolidação da umbanda.

O processo de legitimação da umbanda frente à sociedade brasileira pósdescriminalização em 1945 acabou por omitir ou retirar determinados aspectos do culto umbandista. A aceitação da umbanda pelos brasileiros se deu através da popularização da chamada "umbanda branca", que, teoricamente, não cultuava os orixás africanos como os exus e as pombas giras (NEGRÃO, 1993, p.113). Atualmente no Brasil a umbanda é a religião afro-brasileira com maior quantidade de adeptos, estando concentrada principalmente nas regiões sul e sudeste do país ${ }^{4}$

Diferentemente da Umbanda que se consolidou alinhando-se ao Espiritismo Kardecista europeu, o Candomblé é constantemente associado à cultura Africana, sendo compreendido como uma reconstrução das práticas comuns nos países africanos. O Candomblé, também conhecido como Xangô e Batuque, tem raízes

\footnotetext{
3 Há que se destacar a existência de cultos semelhantes a Umbanda antes do referido acontecimento. Entretanto, devido a fatores como a predominância da oralidade e a criminalização desses rituais são poucos os registros que narram essa parte da história.

${ }_{4}$ Fonte: https://sidra.ibge.gov.br/Tabela/2094. Data de acesso: 04/06/2019.
} 
ligadas à cultura Iorubana (BERKENBROCK, 2019). De acordo com os boletins policiais, a primeira utilização do termo "candomblé" se deu em 1826 fazendo referência ao local em que escravizados fugitivos se abrigaram após uma revolta (BERKENBROCK, 2019).

A consolidação das práticas que atualmente reconhecemos como pertencentes ao Candomblé se deu através dos movimentos sincréticos ocorridos entre as religiões africanas e o catolicismo dentro de instituições aparentemente católicas, as confrarias. Como afirma Roger Bastide, as confrarias e as irmandades dos negros comumente resultaram em terreiros de candomblé (BASTIDE, 1971, p.183). As confrarias eram disponibilizadas aos negros pela Igreja Católica como forma de suprir a carência religiosa deixada pelos senhores de escravos. Entretanto nessas confrarias os escravizados conseguiram se organizar socialmente de forma a reproduzir ou adaptar os sistemas organizacionais das sociedades africanas, auxiliando na conservação e na propagação de seus valores originais (BASTIDE, 1971, p.79). Dando margem para a afirmação de que muitos terreiros de candomblé nasceram de confrarias ou irmandades católicas há a história do Terreiro do Engenho Velho, na Bahia. De acordo com relatos, o terreiro existente desde meados de 1790 surgiu dentro da irmandade "Senhor Bom Jesus dos Martírios dos crioulos naturais da cidade da Bahia.” (BERKENBROCK, 2019).

Portanto, ao contrário da Umbanda, não houve um acontecimento único que marcasse o surgimento do candomblé, visto que o seu surgimento e consolidação como religião partiu de um longo processo de resistência cultural dos negros escravizados. Atualmente os terreiros de candomblé são independentes entre si, possuindo regras próprias que guiam a conduta de seus iniciados bem como as atividades exercidas no local (BERKENBROCK, 2019). Entretanto a unidade que constrói o candomblé, como a compreensão do Aiye e Orum, a crença nos orixás, entre outros, se faz presente em todos os terreiros.

Além da Umbanda e do Candomblé existe uma multiplicidade de tradições religiosas que podemos compreender como religiões afro-brasileiras. Em cada região do país as tradições africanas sobreviveram à sua maneira, fato que culminou na pluralidade de religiões de matriz africana no Brasil (BERKENBROCK, 2019). Como dito anteriormente, uma considerável parcela das religiões que integram essas tradições não seguem um padrão único que as identificam como tal. Cada terreiro tende a possuir a sua forma particular de lidar com os vários elementos das tradições 


\section{SACRILEGENS

que os compõem (BERKENBROCK, 2019). Além disso, são diversas as possíveis combinações que ocorreram entre diferentes tradições religiosas, como é o caso do sincretismo afro-brasileiro e afro-indígena (BERKENBROCK, 2019). Volney Berkenbrock cita em seu texto "Formações religiosas afro-brasileiras" (2019) cerca de dez tradições religiosas afro-brasileiras existentes no país. Como destacado pelo referido autor, nas regiões norte e nordeste do Brasil prevalece o sincretismo entre as religiões africanas e as indígenas, como acontece na Pajelança e no Catimbó (BERKENBROCK, 2019). Nessas religiões marcadas pelo encontro das culturas africanas e indígenas o uso da Jurema, uma planta utilizada para provocar o transe, a ausência dos atabaques e as atividades religiosas comandadas pelo Pajé são as principais características dessas religiões apontadas por estudiosos como pertencentes à classe de sincretismo afro-indígena (BERKENBROCK, 2019). Para além dessas o autor cita a Casa de Mina, o Xangô, o Jarê, o Candomblé de Caboclo, o Canjerê, o Vale do Amanhecer, entre tantas outras (BERKENBROCK, 2019).

\section{Considerações finais}

Neste artigo foi abordada a relação do sincretismo religioso com a formação das religiões afro-brasileiras, em especial a umbanda e o candomblé. Enfatizando o movimento sincrético ocorrido entre o catolicismo ibérico e as religiões africanas, este estudo buscou compreender como os escravizados viabilizaram a preservação de determinados aspectos da sua cultura, dentre eles, as práticas religiosas. Conservar determinados aspectos de sua cultura era de fundamental importância para a sobrevivência dos africanos que foram escravizados no Brasil, uma vez que suas compreensões sobre o funcionamento do mundo e das relações sociais eram baseadas nesses elementos. Como apontado por Roger Bastide em seu livro "As religiões africanas no Brasil”: "O africano, com a destruição racial das linhagens, dos clãs, das aldeias ou das realezas, apegava-se tanto mais a seus ritos e seus deuses, a única coisa que lhe restara de seu país natal, o tesouro que pudera trazer consigo" (BASTIDE, 1971, p.219).

A imposição do catolicismo ibérico e a marginalização dos africanos escravizados no Brasil tiveram grande impacto na vida desses indivíduos. Como visto neste texto, o descaso dos senhores de engenho com a catequização de seus escravos e a similaridade entre as formas as quais se praticava o culto aos santos católicos e aos 


\section{SACRILEGENS

orixás foram pontos importantes para o sucesso da preservação de aspectos das religiões nativas dos escravizados.

Tendo em vista todo o processo de escravização que deu início à formação das religiões afro-brasileiras podemos apontar essas tradições religiosas como sendo um exemplo de resistência frente à todo esse processo histórico de escravização de negros africanos no Brasil, e contra toda a violência que permeou a vida dos africanos neste país durante anos. Bastide aponta em seus estudos como, em certa medida, os escravizados não resistiam ao batismo, símbolo da conversão, entretanto não se pode desconsiderar o contexto social no qual eles estavam inseridos: Uma sociedade de classes onde a dos escravizados poderia ser comparada à dos animais (BASTIDE, 1971, p.185). Considerando esse ponto chegamos a conclusão de que o sincretismo que originou as religiões afro-brasileiras foi, em grande parte, oriundo de uma violência que arruinou uma considerável parcela dos valores simbólicos e cosmológicos dos africanos que foram trazidos ao Brasil.

\section{Referências Bibliográficas}

BASTIDE, Roger. As religiões africanas no Brasil. São Paulo: Editora da Universidade de São Paulo, 1971.

BERKENBROCK, Volney J. A organização religiosa do Candomblé: estrutura, hierarquia, culto e iniciação. 2019. Disponível em: <http://volneyberkenbrock.com/site/index.php?option=com_content\&view=article\&id=329:religio es-afro-brasileiras-cap-5b\&catid=63:2018-03-07-19-27-19\&Itemid =91 > .

Acesso em: 10 jun. 2019.

$<$ http://volney-

- Formações religiosas afro-brasileiras. 2019. Disponível em:

berkenbrock.com/site/index.php?option =com content\&view=article\&id=280:201804-16-21-46-14\&catid=63:2018-03-07-19-27-19\&Itemid=91>. Acesso em: 15 jun. 2019.

. O mundo religioso. Petrópolis, RJ: Vozes, 2019.

O sistema religioso do Candomblé. 2019. Disponível em: $<$ http://volney-

berkenbrock.com/site/index.php?option=com_content\&view=article\&id=328:religio es-afro-brasileiras-cap-5a\&catid=63:2018-03-07-19-27-19\&Itemid=91>. Acesso em: 11 jun. 2019

FERRETTI, Mundicarmo Maria Rocha. RELIGIÃO E SOCIEDADE: religiões de matriz africana no Brasil, um caso de polícia. III Jornada Internacional de Políticas Públicas. São Luís - MA, 28 a 30 de agosto 2007.

FERRETTI, Sérgio E.. Sincretismo afro-brasileiro e resistência cultural. Horizontes Antropológicos, [s.l.], v. 4, n. 8, p.182-198, jun. 1998. FapUNIFESP (SciELO) 


\section{SACRILEGENS}

GOLDMAN, Márcio. Cavalo dos Deuses: Roger Bastide e as transformações das religiões de matriz africana no Brasil. Revista de Antropologia. São Paulo, USP, 2011, V. $54 \mathrm{~N}^{\mathrm{o}}$ 1, p.408-432.

ISAIA, Artur Cesar. Brasil: três projetos de identidade religiosa. In: RODRIGUES, CC., LUCA, TR., e GUIMARÃES, V., orgs. Identidades brasileiras: composições e recomposições [online]. São Paulo: Editora UNESP; São Paulo: Cultura Acadêmica, 2014, pp. 175-202.

MORAIS, Mariana Ramos de; JAYME, Juliana Gonzaga. Povos e comunidades tradicionais de matriz africana: uma análise sobre o processo de construção de uma categoria discursiva. Civitas - Revista de Ciências Sociais, [s.l.], v. 17, n. 2, p.268-283, 23 ago. 2017. EDIPUCRS.

NEGRÃO, Lísias N. Umbanda: Entre a cruz e a encruzilhada. Tempo social; Rev. Sociol. USP, São Paulo, p.113-122,1993.

PRANDI, Reginaldo. Referências sociais das religiões afro-brasileiras: sincretismo, branqueamento, africanização. Horizontes Antropológicos, [s.l.], v. 4, n. 8, p.151167, jun. 1998. FapUNIFESP (SciELO).

SANCHIS, Pierre. O campo religioso contemporâneo no Brasil. In: ORO, Ari Pedro; STEIL. Carlos Alberto. Globalização e religião. Petrópolis: Vozes, 1997.

SILVA, Vagner Gonçalves da. Formação e dinâmica das religiões afro-brasileiras. In: SILVA, Eliana; BELLOTTI, Karina; CAMPOS, Leonildo (orgs) Religião e sociedade na América Latina. São Bernardo do Campo, UMESP, pp 93-100, 2010.

SOUZA, Fabíola Amaral Tomé de. Jornal de Umbanda: construção de discursos em defesa das "boas" práticas religiosas. Em tempo de histórias. Brasília, PPGHIS/UnB No. 30, Jan - Jul 2017. 